\title{
Nurse Educators' Experiences Regarding Subject Competence at a Nursing College
}

\author{
Gugu Ndawo ${ }^{1}$ \\ ${ }^{1}$ Department of Nursing, University of Johannesburg, South Africa \\ Correspondence: Department of Nursing, University of Johannesburg, P.O. Box 524, Auckland Park, 2006, South \\ Africa. Tel: 27-11-559-6984. E-mail: gugun@uj.ac.za
}

Received: October 24, 2018 Accepted: January 24, 2019 Online Published: March 25, 2019

doi:10.5539/gjhs.v11n4p138 URL: https://doi.org/10.5539/gjhs.v11n4p138

\begin{abstract}
Nursing colleges, when faced with the difficulty of obtaining suitable candidates for vacant teaching posts, often assign the remaining nurse educators to teach in the understaffed areas even though they lack expertise in that particular subject. The purpose of this study was to gain an understanding of the experiences of nurse educators regarding their subject competence and to make recommendations to facilitate effective teaching and learning at a nursing college. A qualitative, phenomenological research design was used and a total of 20 nurse educators who complied with the inclusion criteria were recruited through purposive sampling. Audiotape recorded phenomenological, individual interviews were conducted and the collected data were analysed using Tesch's protocol of qualitative data analysis. Ethical considerations were adhered to and trustworthiness was ensured. The three themes that emerged were that participants experienced: (1) incompetence, (2) inadequate didactic facilitation skills, and (3) defence mechanism. It is therefore recommended that nurse educators be empowered first in the subject they must teach to improve their self-esteem and teaching skills and as a result, are enabled to facilitate meaningful learning.
\end{abstract}

Keywords: experience, nurse educator, nursing college, subject competence

\section{Introduction}

South Africa is facing a quadruple burden of disease, namely human immunodeficiency virus/ acquired immunodeficiency syndrome (HIV/AIDS) and tuberculosis (TB), non-communicable diseases, high maternal and child mortality, and trauma, which jointly put enormous pressure on public healthcare and its delivery (Department of Health [DoH], 2013, March). Recently South Africa experienced a challenge in achieving the Millennium Development Goals (MDGs) in spite of other countries making successful progress in these goals globally (Mulaudzi, Phiri, Peu, Mataboge, Ngunyulu \& Mogale, 2016). These pressures necessitate that the healthcare system in South Africa has highly competent professional nurses who possess the expertise to manage them effectively and successfully. For decades, nursing education has been urged to produce learners with intellectual capacity to intelligently transform information presented to them to care for the patients appropriately. These graduates must be lifelong learners who are able to deal with constant changes in the healthcare system and global citizens who are internationally competitive (Council on Higher Education [CHE], 2014, January; DoH, 2006; South African Nursing Council [SANC], 1992a). Therefore nurse educators must create and maintain a learning environment conducive to intellectual engagement that will allow learners to develop necessary skills so that they use the absolute information to create new, relevant knowledge in the management of these pressures. However, to train and produce this kind of a professional nurse, nurse educators who are experts in their fields of teaching are indispensable.

These expert nurse educators must possess in-depth subject knowledge, skills and expertise (SKE) to continuously challenge and encourage learner's capacity to interpret scientific data for effective nursing actions, draw conclusions and exercise independent judgment (Ndawo, 2017). An in-depth subject knowledge, as a frame of reference, would assist nurse educators to use innovative pedagogical strategies to scaffold active learner participation and ensure creation of an environment conducive for learners to co-construct their own knowledge. Expert nurse educators use their own relevant real-life experiences and examples that have relevance to learners' academic lives to base their teaching and maintain strong relations with the clinical environments to keep their experiential clinical knowledge updated. Furthermore, they use innovative pedagogical strategies that utilise research methods, which are appropriate and applicable to their subjects to assist learners to acquire higher order 
thinking skills to care for patients burdened with diseases (Hassanzadeh, Hosseini, \& Honarbakhsh, 2015).

Expert nurse educators are cognisant of valuable subject content that learners have difficulty to understand, which translate to learners being unable to utilise such content in the construction of their own meaningful knowledge. They then set aside sufficient time and spend it effectively on such challenging subject areas to ensure mastery. They remain sensitive to the fact that there are rapid changes and developments in nursing education globally that makes teaching their subjects highly complex. These nurse educators know that to meaningfully teach a learner who will be able to deal with these constant challenging changes in the real world, they must remain highly adaptive, flexibly and fluently assimilating different types of knowledge in teaching their subjects (Yidana, 2017). The dynamic, fluid and never static nature of their subjects make expert nurse educators lifelong learners. Therefore a nurse educator with in-depth subject knowledge, good facilitation skills and positive values is indispensable in the facilitation of deep knowledge, empowering skills, pertinent values and positive attitudes of learners in nursing education

\subsection{Problem Statement}

There is an exodus of nurse educators that results in insufficient numbers and puts a strain on nurse educators who are left behind (DOH, 2013, March). When nursing colleges are faced with the difficulty of obtaining suitable candidates for vacant teaching posts, they often assign the remaining nurse educators to teach in the understaffed areas even though they lack expertise in the particular subject. This assignment is merely to cover the shortfall of competent and skilled nurse educators (Cash, Doyle, Von Tettenborn, Daines \& Faria, 2011; McDermid, Peters, Daly \& Jackson, 2013), who are expected to teach nursing subjects based on knowledge obtained during their own basic training and in which they have minimal KSE. Similarly, at the nursing college under study, some nurse educators were assigned to teach nursing subjects in which they had limited KSE forcing them to base their teaching on textbook knowledge only. Each subject has its own didactic structures thus the unique nature and the core concepts of this particular subject requires the nurse educator to have an in-depth understanding that will influence the decisions as to how the subject should be taught (Samuels, 2015).

Lack of such understanding results in nurse educators developing inauthentic learning tasks without any real-world relevance. They use pedagogical strategies that limit active participation and interaction (Hassanzadeh et al., 2015). They have difficulty explaining concepts at high conceptual level, diagnosing and challenging learners' misunderstandings and misconceptions adequately (Walsh, Fitzmaurice \& O'Donoghue, 2017). In spite of this continued practice, there was no evidence of previous research that was found to have explored the experiences of nurse educators who teach nursing subjects with limited KSE at this nursing college. It was important to concentrate on these nurse educators because of the impact that the practice might have on education and training of professional nurses who will subsequently be expected to effectively and successfully manage the diseases in the country. These professional nurses will also be expected to engage in critical discourse, conversations and debates with their global counterparts in achieving the sustainable developmental goals (SDGs) (Ndawo, 2017; South African Qualifications Authority [SAQA], 1995, October). By understanding the lived experiences of these nurse educators, this study aimed to present recommendations for college principals to support nurse educators in their endeavour to produce knowledgeable and competent professional nurses who will deliver care to patients burdened with diseases, within their real context. Against this background and problem statement, the researcher thus wished to explore the following question: What are the experiences of nurse educators regarding their subject competence at a nursing college?

\subsection{Research Purpose}

This study aimed at gaining an understanding of the lived experiences of nurse educators regarding their competence of teaching nursing subjects in which they have limited knowledge, skills and expertise (KSE).

\subsection{Definitions of Key Concepts}

\subsubsection{Nurse educator}

A nurse educator is a person who communicates knowledge, diagnoses academic needs, formulates innovative strategies to facilitate learning in various ways and evaluates learning to develop learners' higher order thinking skills (Ndawo, 2017). In this study, a nurse educator is a person who teaches a nursing subject with limited KSE of that particular subject.

\subsubsection{Experience}

Experience is knowledge gained by nurse educators through their day-to-day engagement of teaching a subject in which they have limited KSE and how these engagements influence their teaching, learning and assessment roles 
(Gray, Grove, \& Sutherland, 2017).

\subsubsection{Subject Competence}

According to Abid, Hussain, Tariq, Saeed and Shoaib (2017), subject competence is the knowledge, facilitation skills, attitudes and experience that a nurse educator possesses in a subject that influence learning in learners.

\subsubsection{Nursing College}

A nursing college is an education institution where nursing education is offered as permitted by the Nursing Act (Act no. 33 of 2005, as amended). The nursing college where the experiences of nurse educators regarding subject competence were sought is situated in Gauteng province, South Africa.

\section{Method}

\subsection{Research Design}

A qualitative, descriptive phenomenological research design was employed in this study. A phenomenological research approach captures the essence of the lived experiences of participants and the manner in which they view the world, while focusing on the perception of their subjective reality (Moustakas in Creswell, 2013). Through asking questions and probing, this research design produced rich description and provided insight and understanding into nurse educators shared experience and its impact on the academic activities from their very own perspectives (Creswell, 2013). A descriptive phenomenology was used, which involved direct exploration, analysis and in-depth description of teaching a nursing subject with limited KSE as described by nurse educators without the researcher constructing meaning out of their lived experiences (Streubert \& Carpenter, 2011). Therefore nurse educators' experience was told and described as exactly understood by them. The researcher through suspending their own preconceived beliefs and opinions about the experience maintained objectivity (Creswell \& Poth, 2018). To ensure bracketing and self-detachment, honest accurate data analysis and interpretation of findings was done by holding meaningful discussions with the independent coder, study supervisor and academic peers on the collected data and providing thought-provoking reflections on the reflective journal that was kept by the researcher (Collins, Onwuegbuzie, Johnson, \& Frels, 2013; Newton, Rothlingova, Gutteridge, Lemarchand, \& Raphael, 2012). The setting for the study was a nursing college situated in Gauteng, a northern province of South Africa. In this nursing college the practice of teaching a nursing subject with limited KSE still existed. Therefore this research design provided the researcher with an opportunity to explore in detail the lived experiences of nurse educators regarding their subject competence at this nursing college therefore providing answers to the research question.

\subsection{Sample and Sampling Method}

The target population was 20 nurse educators with whom data saturation was reached. These nurse educators were purposively selected as the study sample as they were assigned to teach nursing subjects in which they had limited KSE due to the shortage of staff. They could therefore provide rich, thick data that answered the research question (Gray et al., 2017). The inclusion criteria were nurse educators who had completed the four-year comprehensive nursing diploma programme (SANC, 1985), held an additional qualification in nursing education (SANC, 1987), and had two or more years of teaching experience in higher education. They had been assigned to teach a nursing subject in which they had limited KSE uninterruptedly for at least two years and had willingly and voluntarily consented to participate in the study. The exclusion criteria were all nurse educators who have never taught a nursing subject in which they had lacked KSE.

Table 1. Nurse educators' demographic information

\begin{tabular}{lllllll}
\hline $\begin{array}{l}\text { Teaching } \\
\text { experience }\end{array}$ & Highest qualification & Race & Gender & Age & Position in nursing \\
\hline & $\begin{array}{l}\text { Nursing education with specialty } \\
\text { (post-basic) studies }=16 ;\end{array}$ & $\begin{array}{l}\text { African }=18 ; \\
\text { Asian }= \\
\text { Coloured }=1\end{array}$ & Female $=19 ;$ & Male $=1$ & years & Senior lecturer $=12$ \\
& Master's $=3 ;$ & & & &
\end{tabular}

Note. Table 1 demonstrates the demographic information of the 20 nurse educators who took part in the study. The specialties referred to were critical care, occupational health, community health nursing and advanced midwifery. 


\subsection{Data Collection}

Data were collected by the researcher using in-depth, semi-structured, phenomenological, individual interviews that were conducted in English in the participants' offices, homes and their departmental boardrooms. The individual interview was a method of choice because while it used scope and depth to explore the lived experiences, it also allowed considerable flexibility of time, availability and accessibility of each participant which proved difficult when they were invited to participate in focus groups. As a result, the process of data collection did not interfere with the facilitation of academic activities of the participants. Later, this method of data collection proved to be the best due to the sensitivity of the phenomenon that was at hand (De Vos, Strydom, Fouché \& Delport, 2011). The settings used for the data collection process were chosen by participants thus provided the context within which they felt free and comfortable to talk about their lived experiences and took own meaning from themselves (Creswell, 2013). The interviews were audiotape recorded with the permission of the nurse educators therefore providing the researcher with accurate verbatim accounts of their lived experiences thereby increasing the credibility of the findings. Field notes were also taken to enrich the collected data. The question that directed the interviews was: What was your experience of teaching a subject in which you had limited knowledge, skills and expertise? Facilitative communication clarifying techniques such as probing, listening, silence, paraphrasing and summarising were employed to ensure a detailed exploration of the data (Murphy \& Dillon, 2011).

\subsection{Data Analysis}

Tesch's protocol of open coding was used to manually analyse all the audiotaped and verbatim transcribed interviews together with field notes to capture the 'essence' of the lived experiences being studied by identifying its fundamental parts (Creswell, 2013). The data analysis was done by the researcher as well as an independent coder using steps as outlined in Table 2 below. The independent coder was an expert who was purposively selected because of her seven-year experience in qualitative research data analysis. A consensus discussion meeting between the researcher and the independent coder was held to agree on the independently identified themes thus establishing the credibility of the analysed findings. Eleven (11) follow-up individual interviews were conducted with participants to verify the transcribed data and identified themes as true accounts and description of their lived experience.

Table 2. Tesch's eight steps used during data analysis

\begin{tabular}{ll}
\hline Step 1 & $\begin{array}{l}\text { The transcribed interviews were repeatedly and carefully read to get a sense of the whole and gain accurate } \\
\text { information }\end{array}$ \\
\hline Step $\mathbf{2}$ & $\begin{array}{l}\text { Whilst reading the transcripts individually, the underlying meanings in the information was looked for and as } \\
\text { thoughts came to mind, they were written in the margin }\end{array}$ \\
\hline Step $\mathbf{3}$ & From the information in the margin, a list of similar topics was made \\
\hline Step $\mathbf{4}$ & Similar topics were clustered together and arranged into major topics, unique topics and leftovers \\
\hline Step $\mathbf{5}$ & Topics were checked against raw data and were abbreviated as codes next to the appropriate segment \\
\hline Step $\mathbf{6}$ & The most descriptive wording for the topics were found and were turned into themes \\
\hline Step 7 & Similar themes were grouped together to reduce their numbers. Each theme was abbreviated \\
\hline Step 8 & Each abbreviated theme was alphabetised \\
\hline Step $\mathbf{9}$ & Data belonging to each theme was assembled and the existing data was re-coded for final themes \\
\hline
\end{tabular}

\subsection{Trustworthiness}

Lincoln and Guba's (1985) four strategies of establishing trustworthiness of qualitative data, namely credibility, transferability, dependability and confirmability, were used. Credibility was ensured by spending time with the nurse educators until data saturation. Field notes were taken and observations were made. Member checking was done during each interview and through 11 follow-up interviews with the participants to ensure that the findings were a true reflection of their lived experience. The researcher worked with five of the participants for three years as their assessment paper moderator through approved affiliation between this nursing college and the researcher's university to ensure nursing college's quality assurance. Transferability was ensured by providing a demographic information of the participants (see Table 1), the sampling strategy and study setting. Moreover, a dense description of collected data, which was supported by direct quotations from the participants was provided. Dependability of the study was enhanced by providing a thick, rich description of the research methodology. For a 
possible audit trail, all raw data including consents, audiotape recorded interviews, transcripts and analysed data findings were kept accessible to the supervisor and independent coder as well as available to any other interested researcher. Confirmability was ensured by a confirmability audit trail of the raw data and the use of an independent coder (Lincoln \& Guba, 1985; Polit \& Beck, 2018).

\subsection{Ethical Considerations}

Ethical decisions were observed based on the guidelines described by Dhai and McQuoid-Mason (2011) which involve the principles of respect for persons, beneficence, non-maleficence and justice. After explaining the proposed research with reference to the purpose of the study and clarifying any questions that the participants had, informed consents were obtained in which they stated that they participated voluntarily and permitted the use of an audiotape recorder. Participants were also informed of their right to withdraw from the study at any time without penalty. Pseudonyms were used to ensure anonymity and the audiotape recorded interviews, field notes and transcriptions were locked away in a safe place for two years after which they were destroyed to ensure confidentiality. The research study posed no risk or harm to the participants and no incentives were given for their participation in the study. Ethical clearance was granted by the University of Johannesburg's, Faculty of Health Sciences Research Ethics Committee (AEC 43-01-2012).

\section{Results}

The themes that emerged from the study were that participants experienced incompetence (due to inadequate subject KSE); inadequate didactic facilitation skills; and (demonstrated negative attitude as a) defence mechanism.

\subsection{Theme 1: Incompetence}

The study revealed that nurse educators were affected negatively by the experience of teaching subjects with which they were not acquainted. They felt incompetent when they were assigned to teach a subject in which they had limited KSE due to shortage of staff. Some participants stated the following:

'I felt stupid ... like ... I was really dumb and I didn't know what I was doing.' (Participant \#10)

'I want to teach a subject that I feel is my field of expertise. Standing in front of the class with little knowledge of the subject makes me feel inadequate and incapable.' (Sounding concerned) (Participant \#7)

'I became anxious when it was time for me to go to class because I didn't know what was in store for me ... I didn't have enough knowledge of this subject ...' (Participant \#15)

During interviews, participants explained that when they started at this nursing college they were assigned nursing subjects that no other nurse educator wanted to teach. One participant said:

'When I started at this college I taught BNS (Biological and Natural Sciences) because no one wanted to teach it as it is viewed as a very difficult subject. I was not acquainted with the subject and I felt useless.' (Frowning) (Participant \#7)

'... my colleagues refused to teach BNS ... and as I came from a different specialty I felt inadequate and useless and on one cared' (Sounding saddened) (Participant \#11)

It was evident that participants were aware of the fact that they needed to have gained in-depth knowledge and experience in the clinical or work environment before they could teach the subject. They also felt that this practice was dishonourable. Participants reported that:

'Reality is, I needed deep knowledge and experience of the subject before I could teach it to gain confidence and be successful.' (Sounding desperate) (Participant \#12)

'... I don't have experiential knowledge which could give me confidence because when you have it (experiential knowledge) you teach from your heart but with BNS I don't have it. '(Participant \#7)

'... I truly believe that this exercise of teaching what I don't even know and understand is highly unethical.' (Participant \#3)

\subsection{Theme 2: Inadequate Didactic Facilitation Skills}

The study also found that nurse educators with limited subject KSE experienced inadequate facilitation skills to teach that subject. They could not think "outside the box" when it came to the use of innovative pedagogical strategies. Some participants explained:

'I know I don't teach students effectively because I'm uncertain of what I'm saying which negatively affect the way I teach.' (Sounding desperate) (Participant \#2)

'... my teaching skills became non-existent ...' (Participant \#19) 
'I didn't use innovative teaching strategies because I couldn't see how I could make it work.'(Participant \#11)

Most participants felt that it was important to have subject knowledge to develop learners' higher-order thinking skills (HOTS). They said:

'... I can't develop students' HOTS because I lack knowledge, skills, values and attitude towards this subject ...' (Frowning, sounding frustrated) (Participant \#2)

'How do you facilitate the development of the imperative skills such as critical thinking when you don't know what and how you are teaching?' (Participant \#1)

Moreover, lack of subject knowledge resulted in a lack of deeper engagement with the students and subject. One participant noted:

'When I was standing there and the only thing that went through my mind was, "I wish the class was over", because of inadequate content knowledge, it was impossible for me to see who was listening, understanding and who wasn't.' (Participant \#9)

\subsection{Theme 3: Defence Mechanism}

The findings also revealed that some participants lost their self-esteem when learners asked them questions that required experiential knowledge, which led them to act negatively towards learners to defend themselves. Some participants highlighted that:

'My self-esteem got tainted and bruised ... I didn't want to be challenged by students, so I blocked them by being unaccommodating. '(Avoiding eye contact) (Participant \#12)

'... this (teaching BNS) took a toll on me ... I became a monster but I didn't and still don't mean to ... '(Participant \#20)

Most participants were aware that they behaved in an uncivil manner to conceal their lack of knowledge. Some participants commented:

'Students say, "You always say we can consult any time but when we come to your office you are irritable and unapproachable”...'(Participant \#3)

'Student even say that we use our power position to cover up our inadequacies. '(Participant \#4)

Participants were also cognisant of the fact that when they lose control of the teaching situation they experienced emotional stress that resulted in negative behaviour, which in this study manifested as not engaging in clinical accompaniment. Some participants highlighted this by saying:

'I didn't do clinical accompaniment because I didn't have deep knowledge and experience of the subject ... so what was I supposed to do when I was quizzed by the students in the wards?' (Stressing the point) (Participant \#14)

'... I didn't feel confident and committed to accompany them (students) because ... (pause) ... I lacked knowledge and experience ...' (Participant \#13)

\section{Discussion}

\subsection{Theme 1: Incompetence}

According to Du Plessis, Carroll and Gillies (2015), the feeling of incompetence is common and results from subject inadequacies. As a result, nurse educators deliver the learning content shallowly and at a fast pace leading to superficial rather than deep learning. Of importance is that even the experienced nurse educators when assigned to facilitate a subject in which they have limited KSE, feel incompetent (Kola \& Sunday, 2015; Mizzi, 2013). Whilst they are acquainting themselves with the subject, nurse educators operate in a "safe" mode, which involves presenting paraphrased, abstract and meaningless information from the textbook. Thus circumventing meaningful, realistic, active engagement in intellectual critical discourse where there is interaction, negotiation and exploration of diverse viewpoints that promote dialogic dialectic thinking in learners (Gibson, O’Toole, Dennison, \& Oliver, 2013). They are unable to mediate effective learning, provide real-life examples or respond to real-life questions with real-life answers. Moreover, the risk of teaching inaccurate information to learners is great since they are unable to appropriately and effectively critique, critically examine and evaluate the information for credibility and reliability (Jadama, 2014). This implies that they have difficulty providing learners with developmental, positive, constructive feedback that leads to learners' academic and professional development.

Some educators felt as if they are only given subjects that others do not want to teach. This rejection is due to the subject being regarded as "difficult" or "boring", which impedes the successful facilitation of that subject (Peters, 2014). Inadequate subject knowledge denies nurse educators the opportunity to engage with learners who bring complex, challenging, real-life questions about the learning content (Jadama, 2014). While nurse educators 
acknowledge their own subject incompetence, learners also recognise these incompetencies and as a result, believe that educators do not have the necessary knowledge. Such observations are easily made when educators are constantly correcting themselves in front of the learners and are unable to answer the critical challenging questions that the learners pose. Often questions expose the specific learning content that the nurse educator is not familiar with leading to a display of lack of self-confidence in their teaching abilities and loss of respect from the learners (Gibson et al., 2013). The inability to answer learners' question and expose them to the complexities of the specific subject may impact negatively on subsequent learning since it can lead to learners experiencing difficulty in applying sufficient subject knowledge to practice in future.

It is important that nurse educators are well educated and experienced in their subject to maintain, develop their expertise further and become lifelong learners. With in-depth subject KSE, nurse educators can effectively assist learners to construct new knowledge and subsequently develop their current cognitive level to a much higher-order cognitive level (Rowe, Bozalek \& Frantz, 2013). However, how can they assist in the construction of new knowledge when they themselves struggle to connect subject-specific concepts (Du Plessis et al., 2015)? Most participants also stated that they needed deep experiential knowledge of an assigned nursing subject for them to be able to competently, effectively and meaningfully facilitate learning of that particular subject. However, they were assigned to teach a nursing subject on the basis of knowledge obtained during their basic nursing training programme without any in-depth practical experience after obtaining such basic qualification. Due to the absence of experiential knowledge in a subject, nurse educators cannot integrate and apply new knowledge in a meaningful way therefore cannot explain the subject's relevance to learners' lives. They cannot relate to real-life examples and experiences when teaching since they do not have this experience. It was also interesting to note that the nurse educators felt that it was unethical to teach nursing subjects in which they were not experts as they had a responsibility to teach in a manner that contributed to the learners' academic success. According to Gibson et al. (2013), when nurse educators teach nursing subjects in which they lack KSE, their effectiveness in facilitating meaningful learning is hindered. While nurse educators are acquainting themselves with the subject matter to a point where they are competent, this is a period during which learners are academically compromised.

\subsection{Theme 2: Inadequate Didactic Facilitation Skills}

Effective facilitation of interactive, integrative and constructive learning is dependent on in-depth subject knowledge. Inadequate subject knowledge is one of the main factors that limits the development of educators' effective didactic facilitation skills which are required to guide learners through a dynamic learning process based on focused questions and critical reflection (Mizzi, 2013). Pedagogical content knowledge affords the nurse educator a "flexible and multi-faceted comprehension" used to generate and communicate multiple explanations of the same concepts thus facilitating meaningful learning for a diverse population of learners (Shulman in Ochieng'Ong'ondo, 2017). They are thus empowered to confidently facilitate subject content using real-life examples that are learner-centred. Nowadays nurse educators use lesson plans integrated with a variety of resources such as technology and clear guidelines of what will be done, how, when and why it will be done (Gaciu, Dalzell, Davis, Diamond, \& Howard, 2017). Such lesson plans are excellent didactic facilitation tools that assist nurse educators to observe, notice, interpret and evaluate the quality of learning within their learning environments. With ineffective didactic facilitation skills, educators may fail to assess, identify and address their own knowledge gaps while taking responsibility for the development of planning, teaching and assessment skills. Therefore they cannot improve their subject knowledge (Hultman, Löfgren, \& Schoultz, 2012).

Good didactic facilitation skills facilitate the development of learners' higher-order thinking skills such as critical and reflective thinking, problem-solving, rational decision-making and clinical judgment, which are of utmost importance in an ever-changing healthcare environment. No educator can facilitate subject matter that they themselves do not fully understand therefore the development of such required higher-order thinking skills is hindered by inadequate subject knowledge (Jadama, 2014). Poor pedagogical content knowledge also results in the failure of educators to engage learners in innovative pedagogical strategies that develop higher-order thinking skills such as interdisciplinary community outreach projects, argumentation and debates (Gibson et al., 2013). Nurse educators often lack creativity that affords them opportunities to create rich, dynamic and interactive learning environments that provoke learners' curiosity, inquisitiveness and critical inquiries that develop such skills. They are challenged to facilitate the connection of new information to prior knowledge that scaffolds the process of meaningful knowledge construction between learners while relating to learners' cultural backgrounds, academic and social interests and the real world (Du Plessis et al., 2015). Participants also felt that it was important to collaborate with educators from other disciplines to facilitate their learners' higher-order thinking skills. This view is supported by Reeves, Herrington and Oliver (in Inder \& Withell, 2013) who found that an authentic activity must be integrated and applied across relevant disciplines to develop multiple viewpoints patient's complex problem since there is no single correct solution to such a problem. This implies that nurse educators must 
be able to engage in critical discourse with the interdisciplinary community of educators regarding the subject matter that is common and relevant to the academic needs of their learners. But how can nurse educators be expected to participate and meaningfully contribute to collaborative critical discourse when they lack pedagogical content knowledge? Lack of pedagogical content knowledge results in apprehension to engage in subject-related critical discourse (Hobbs \& Campbell, 2015).

Nurse educators without pedagogical content knowledge are unable to respond to feedback from the complex learning environment that helps improve their didactic facilitation skills. Therefore they fail to diagnose learners' academic needs and provide evidence-based solutions to overcome learners' difficulties (Hultman et al., 2012). This implies that they are unable to assess and identify at-risks learners to scaffold, mentor and coach them to meaningful learning and academic success. Learners are not engaged in $21^{\text {st }}$ century activities that encourage perseverance with ambiguity, uncertainty and risk-taking. Learners remain dependent and do not recognise and value learning from their own mistakes since an emotionally safe learning environment is not created. A lack of good didactic facilitation skills results in a reduced amount and intensity of meaningful participation in knowledge construction, further minimising the development of higher-order thinking skills demanded by the very nature of the dynamic, challenging healthcare environment (Bimray, Le Roux, \& Fakude, 2013).

\subsection{Theme 3: Defence Mechanism}

It is not unusual for educators to exhibit negative attitude as a defence mechanism when asked challenging questions that require in-depth subject KSE. As a result, the educator's self-esteem suffers, which in turn influences the relationships with their learners (Du Plessis et al., 2015). Learners' thought-provoking questions could arise from cognitive disequilibrium resulting from their prior knowledge and experiences that might be more than that of the nurse educator with limited KSE (Baraz, Memarian, \& Vanaki, 2015). However, due to a lack of subject KSE, nurse educators do not ask related or higher-order questions that probe and stimulate prior knowledge and make use of guided logic thinking processes. Instead, they will behave in an uncivil manner to cover up their lack of knowledge.

The use of power by educators to cover up subject incompetence by acting in an aloof manner, not answering thought-provoking questions, discouraging critical discussions, using ineffective didactic facilitation skills and sending a message that learners are a burden, disturbs learners (Beck, 2015). This goes against the grain of good teaching where learners are treated with dignity and where mutual respect and appropriate boundaries are observed (Gibson et al., 2013; Knepp, 2012). The inappropriate behaviour that nurse educators display due to job dissatisfaction and their failure to cope because they have inadequate subject KSE hinders the construction of a trusting, mutually respectful learner-nurse educator relationship that is vital for meaningful learning (Beck, 2015; Du Plessis et al., 2015).

Other studies also observed that learners are often left unaccompanied with insufficient supervision in clinical areas (Inder \& Withell, 2013; Nyhagen \& Strøm, 2016). According to these authors, the practice is due to little enthusiasm and motivation caused by limited subject KSE, lack of commitment and admittance of feelings of being clinically inadequate to support learners. Nurse educators are compelled by law to accompany learners to clinical areas to ensure that competent nursing practitioners who are safe, critical, autonomous and independent are trained (DoH, 2013, March). Their unavailability and inaccessibility means that learners are unable to integrate and apply theory to practice and develop essential competencies. A good fit between the educator's subject preference and their ability to teach creates high levels of satisfaction and motivation to carry out teaching duties with diligence and success. This good fit was perceived to be lacking by some of the participants. When there are uncertainties, loss of confidence, amotivation and dissatisfaction, nurse educators shift their primary focus from facilitating meaningful learning to their own needs as they teach for survival on a day-to-day basis (Du Plessis et al., 2015). When they lose control of the teaching situation they experience emotional stress that results in negative behaviour, which in this study manifested as not engaging in clinical accompaniment. Their exhibited negative attitude makes learners feel undervalued and demotivated to learning that particular subject leading to difficulty in attaining their academic goals. The limited academic and clinical support may be insufficient to assist them to learn to cope with challenging, ever-changing healthcare environment in future.

\section{Limitations}

The study provided rich information about the challenges experienced by nurse educators at a particular nursing college who teach nursing subjects in which they lack KSE. However, these were unique and personal experiences and the use of a purposive sampling method may render the sample not representative of the entire population thus the findings of the study cannot be generalised to other nursing colleges.

\section{Recommendations}

It is recommended that nurse educators be empowered first in the subject they must teach to improve their 
self-esteem through being assigned posts in accordance with their qualifications, continuous experience and practical expertise to maximise successful teaching and meaningful learning. A subject-specialist mentor should be assigned to improve the nurse educator's subject knowledge base so that they are able to make informed decisions and develop their subject-related expertise (Ndawo, 2017). Provision of support such as access to all relevant teaching resources and continuous professional development of the assigned nurse educator is important to facilitate easy transition, improve subject KSE and didactic facilitation skills, which in turn will improve learner success (Gibson et al., 2013; Kenny \& Hobbs, 2015). Continuous in-service training that focuses on academic and professional training and subject didactics should be provided to improve facilitation proficiency of nurse educators (Hultman et al., 2012). For arears of further research it is recommended that the impact of the competence of nurse educators be compared between the subject they teach with KSE to those that they teach without. Furthermore, a meta-synthesis on the previous existing studies be carried out to integrate findings and thus develop comprehensive recommendations.

\section{Conclusions}

The findings demonstrated that this study extended previous research on the phenomenon of educators who teach subjects with limited KSE since all themes made reference to and were supported by previous research. Therefore the study adds on the existing body of knowledge. The findings suggest that while nurse educators are acquainting themselves with the nursing subject the cohorts of learners are not being adequately prepared to manage burden of diseases effectively and successfully. The findings indicate that when nurse educators were assigned to teach nursing subjects in which they had limited KSE, they felt incompetent, have inadequate didactic facilitation skills and developed negative attitudes to learners as a defence mechanism. The aim of nursing education is to produce a nursing workforce that is equipped to deal with the demands of an ever-changing clinical nursing environment. Nurse educators must thus be able to fulfil this aim by educating learners within their relevant speciality-teaching qualifications and professional domain, however, the reality is that this does not always happen. Learners must learn to be independent, autonomous and critical individuals who will be able to provide holistic, comprehensive care to clients through authentic learning. Nurse educators will always have an influence on learners. Learners deserve nurse educators who are knowledgeable, have effective didactic facilitation skills and positive attitudes to support them throughout their training. This support improves their chance of academic success and from which they learn the meaning of true altruism.

\section{Acknowledgements}

The author declares that this research study did not receive any specific grant from any funding agency. The author wishes to thank all the participants of the study and Professor Mary Chabeli from the Department of Nursing at the University of Johannesburg for her supervisory guidance and support. Ms Y Pawlowksi for language editing this article.

\section{Competing Interests Statement}

The authors declare that there are no competing or potential conflicts of interest.

\section{References}

Abid, N., Hussain, T., Tariq, M. C., Saeed, A., \& Shoaib, A. (2017). Subject matter knowledge competence: An empirical evidence of elementary school teachers. Bulletin of Education and Research, 39(1), 245-250.

Baraz, S., Memarian, R., \& Vanaki, Z. (2015). Learning challenges of nursing students in clinical environments: A qualitative study in Iran. Journal of Education and Health Promotion, 4, Article \# 52. https://doi.org/10.4103/2277-9531.162345

Beck, D. M. (2015), Incivility and student and faculty relationships: implications for revising mentorship programs for nurse educators. SOJ Nursing \& Health Care, 1(1), 1-10.https://doi.org/10.15226/2471-6529/1/1/00103

Bimray, P. B., Le Roux, L. Z., \& Fakude, L. P. (2013). Innovative education strategies implemented for large numbers of undergraduate nursing students: The case of one South African university nursing department. Journal of Nursing Education and Practice, 3(11), 116-120. https://doi.org/10.5430/jnep.v3n11p116

Cash, P. A., Doyle, R. M., Von Tettenborn, L., Daines, D., \& Faria, V. (2011). Working with nurse educators' collective wisdom: Implications for recruitment and retention. Nursing Economics, 29(5), 257-267. PMID: 22372082

Collins, K. M. T., Onwuegbuzie, A. J., Johnson, R. B., \& Frels, R. K. (2013). Practice note. International Journal of Multiple Research Approaches, 7(2), 271-284. https://doi.org/10.5172/mra.2013.7.2.271

Creswell, J. W. (2013). Qualitative inquiry and research design: Choosing among five approaches (3rd ed.). Thousand Oaks: Sage Publications. 
Creswell, J. W., \& Poth, C. N. (2018). Qualitative inquiry and research design: Choosing among five approaches. Thousand Oaks: Sage Publications.

De Vos, A. S., Strydom, H., Fouché, C. B., \& Delport, C. S. L. (2011). Research at grass roots: For the social sciences and human service professions (4th ed.). Pretoria: Van Schaik.

Dhai, A., \& McQuoid-Mason, D. J. (2011). Bioethics, Human Rights and Health Law: Principles and practice. Cape Town: Juta.

Du Plessis, A., Carroll, A., \& Gillies, R. M. (2015). Understanding the lived experiences of novice out-of-field teachers in relation to school leadership practices. Asia-Pacific Journal of Teacher Education, 43(1), 4-21. https://doi.org/10.1080/1359866X.2014.937393

Gaciu, N., Dalzell, L., Davis, J., Diamond, A., \& Howard, S. (2017). Trainee teachers' reflections on approaches to enhance their subject knowledge in physics and mathematics. Teacher Education Advancement Network Journal (TEAN), 9(1), 36-44.

Gibson, S., O'Toole, G., Dennison, M., \& Oliver, L. (2013). Evaluation of Subject Knowledge Enhancement Courses. Annual Report - 2011-12, CooperGibson Research: DoE.

Gray, J. R., Grove, S., \& Sutherland, S. (2017). The practice of nursing research: Appraisal, synthesis and generation of evidence (8th ed.). Elsevier: Saunders.

Hassanzadeh, Z. S., Hosseini, S. R., \& Honarbakhsh, F. (2015). Study of the educational factors contributing to realization of the objectives of entrepreneurial university. International Journal of Advanced and Applied Sciences, 2(10), 1-12.

Hobbs, L., \& Campbell, C. (2015). Pre-service teachers' perceptions of the support, challenges and opportunities associated with teaching out-of-field. Proceedings of the 39th ATEE Annual Conference 2014 "Transitions in teacher education and professional identities", (pp. 213-223). University of Minho, Braga, Portugal.

Hultman, G., Löfgren, R., \& Schoultz, J. (2012). Subject didactics in practice - hidden in the process: A study of teaching logics and classroom cultures. Education Inquiry, 3(1), 3-18. https://doi.org/10.3402/edui.v3i1.22010

Inder, S., \& Withell, A. (2013). A case study of authentic learning underpinned by design thinking and industry collaboration. DesignEd Asia 2013 Conference held at Jockey Club Innovation Tower, Hong Kong: The Hong Kong Polytechnic University.

Jadama, L. M. (2014). Impact of subject matter knowledge of a teacher in the teaching and learning process. Middle Eastern \& African Journal of Educational Research (MAJER), 7(1), 20-29.

Kenny, J., \& Hobbs, L. (2015). Researching with in-service teachers teaching "out of field". Contemporary Approaches to Research in Mathematics, Science, Health and Environmental Education Symposium at Deakin University, Melbourne City Centre, Melbourne, 24 - 25 November 2016.

Knepp, K. A. F. (2012). Understanding student and faculty incivility in higher education. Journal of Effective Teaching, 12(1), 32-45.

Kola, A. J., \& Sunday, O. S. (2015). A review of teacher self-efficacy, pedagogical content knowledge (PCK) and out-of-field teaching: Focussing on Nigerian teachers. International Journal of Elementary Education, 4(3), 80-85. https://doi.org/10.11648/j.ijeedu.20150403.15

Lincoln, Y. S., \& Guba, E. G. (1985). Naturalistic inquiry. Beverly Hills: Sage.

McDermid, F., Peters, K., Daly, J., \& Jackson, D. (2013). 'I thought I was just going to teach': Stories of new nurse academics on transitioning from sessional teaching to continuing academic positions. Contemporary Nurse, 45(1), 46-55. https://doi.org/10.5172/conu.2013.45.1.46

Mizzi, D. (2013). The challenges faced by science teachers when teaching outside their specific science specialism. Acta Didactica Napocensia, 6(4), 1-6.

Mulaudzi, F. M., Phiri, S. S., Peu, D. M., Mataboge, M. L., Ngunyulu, N. R., \& Mogale, R. S. (2016). Challenges experienced by South Africa in attaining Millennium Development Goals 4, 5 and 6. African Journal of Primary Health Care \& Family Medicine, 8(2), 1-7. https://doi.org/10.4102/phcfm.v8i2.947

Murphy, B. C., \& Dillon, C. (2011). Interviewing in action in a multicultural world (4th ed.). USA: Brooks/Cole, Cengage Learning.

Ndawo, M. G. (2017). A model to facilitate authentic learning in learner nurses at a higher education institution (Doctoral dissertation). Retrieved from http://hdl.handle.net/10210/246626 
Newton, B. J., Rothlingova, Z., Gutteridge, R., Lemarchand, K., \& Raphael, J. H. (2012). No room for reflexivity? Critical reflections following a systematic review of qualitative research. Journal of Health Psychology, 17(6), 866-885. http://dx.doi.org/10.1177/1359105311427615

Nyhagen, R., \& Strøm, A. (2016). Postgraduate students' perceptions of high-quality precepting in critical care nursing. Nurse Education in Practice, 21(2016), 16-22. https://doi.org/10.1016/j.nepr.2016.09.002

Ochieng'Ong'ondo, C. (2017). The knowledge base for language teacher education revisited: A review. International Journal of English Language Teaching, 4(2), 27-38. https://doi.org/10.5430/ijelt.v4n2p27

Peters, A. B. (2014). Faculty to faculty incivility: Experiences of novice nurse faculty in academia. Journal of Professional Nursing, 30(3), 213-227. https://doi.org/10.1016/j.profnurs.2013.09.007

Polit, D. F., \& Beck, C. T. (2018). Essentials of nursing research: Appraising evidence for nursing practice (9th ed.). Philadelphia: Wolters Kluwer Health.

Republic of South Africa. (2005). Nursing Act no. 33 of 2005 (as amended). Pretoria: Government Printers.

Republic of South Africa. Council on Higher Education (CHE). (2014, January). Framework for Institutional Quality Enhancement in the Second Period of Quality Assurance. Pretoria: Author.

Republic of South Africa. Department of Health (DoH). (2006). National Human Resources for Health Plan. Pretoria: Government Printers.

Republic of South Africa. Department of Health (DoH). (2013, March). The National Strategic Plan for Nursing Education, Training and Practice 2012/13 - 2016/17. Pretoria: Government Printers.

Republic of South Africa. South African Qualifications Authority (SAQA). (1995, October). South African Qualifications Authority Act (Act no. 58 of 1995). Pretoria: Author.

Rowe, M., Bozalek, V., \& Frantz, J. M. (2013). Using Google Drive to facilitate a blended approach to authentic learning. British Journal of Educational Technology, 44(4), 594-606. https://doi.org/10.1111/bjet.12063

Samuels, S. L. (2015). The evolution of prospective elementary teachers' competencies: Procedural knowledge, mathematical knowledge for teaching, attitudes, and enactment of mathematical practices (Doctoral dissertation). Retrieved from https://scholarworks.montana.edu/xmlui/handle/1/9213

South African Nursing Council (SANC). (1992a). The philosophy and policy of the South African Nursing Council with regard to professional nursing education. Pretoria: Author.

South African Nursing Council (SANC). (1985). Regulations relating to the approval of and the minimum requirements for the education and training of a Nurse (General, Psychiatric and Community) and Midwife leading to registration: Regulation 425 of 1985, as amended. Pretoria: Author.

South African Nursing Council (SANC). (1987). Regulations concerning the minimum requirements for registration of the additional qualification in Nursing Education: Regulation 118 of 1987, as amended. Pretoria: Author.

Streubert, H. J., \& Carpenter, D. R. (2011). Qualitative research in nursing: Advancing the humanistic imperative (5th ed.). New York: Lippincott Williams \& Wilkins.

Walsh, R., Fitzmaurice, O., \& O'Donoghue, J. (2017). What subject matter knowledge do second-level teachers need to know to teach trigonometry? An exploration and case study. Irish Educational Studies, 36(3), 1-34. https://doi.org/10.1080/03323315.2017.1327361

Yidana, M. B. (2017). Relative importance of indicators of teachers' professional skills as perceived by Senior High School Economics teachers in Ghana. Journal of Educational and Social Research, 7(3), 79-93. https://doi.org/10.1515/jesr-2017-0006

\section{Copyrights}

Copyright for this article is retained by the author(s), with first publication rights granted to the journal.

This is an open-access article distributed under the terms and conditions of the Creative Commons Attribution license (http://creativecommons.org/licenses/by/4.0/). 